\title{
A CONCEPÇÃO POLÍTICA DO CURRÍCULO DE FILOSOFIA DO PROGRAMA SÃO PAULO FAZ ESCOLA
}

José Antônio Leandro Filho, Genivaldo de Souza Santos

Universidade do Oeste Paulista - UNOESTE. Mestrado em Educação, Presidente Prudente - SP. E-mail: z2antonio@hotmail.com

\section{RESUMO}

Este trabalho é parte de uma pesquisa maior da Pós-graduação, mestrado da Universidade do Oeste Paulista (Unoeste), com o título "Análise da concepção política do currículo São Paulo faz Escola e o papel da disciplina de Filosofia". Este trabalho buscou refletir sobre a volta da Filosofia no currículo no Estado de São Paulo. Utilizamos a pesquisa bibliográfica com os documentos oficiais e autores e pesquisadores sobre o tema. A partir da leitura e análise entendemos que a Filosofia volta ao currículo em 2005 mas ainda não figura como uma disciplina que é proporcionar os alunos a ter uma análise crítica da realidade.

Palavras chave: Filosofia, Currículo.

\section{THE CONCEPT PROGRAM PHILOSOPHY CURRICULUM POLICY DOES SÃO PAULO SCHOLL}

\begin{abstract}
This work is part of a larger survey of graduate, master's from the University of Oeste Paulista (Unoeste), with the title 'educational policy philosophy curriculum of the state of São Paulo: an analysis from the program São Paulo makes school. This study aimed to reflect on the back of Philosophy in the curriculum in the state of São Paulo. We use the literature to official documents and authors and researchers on the topic. From the reading and analysis understand that philosophy back to the curriculum in 2005 but not yet figure as a discipline that is to provide the students to have a critical analysis of reality.
\end{abstract}

Keywords: Philosophy, Curriculum. 


\section{INTRODUÇÃO}

Sou Educador desde 2006 na rede estadual de São Paulo e sempre presenciei os professores de outras áreas e a gestão considerar a Filosofia como uma disciplina secundária ou simplesmente para preencher o Currículo.

Quando o estado de São Paulo começou a produzir o material didático a ser usado nas aulas de Filosofia me incomodou com o procedimento usado. Imposto sem consultar os professores, ao menos na escola onde lecionava, sobre o Currículo a ser seguido. Mesmo que haja um discurso oficial que o material, caderno do aluno e do professor, seja um norte para se trabalhar nas aulas, sempre fui cobrado sobre a aplicação do mesmo na integra. Cada final de bimestre temos preenchido um formulário explicando em qual situação de aprendizagem estava trabalhando com os respectivos anos.

Ao ter o material em mão sempre achei os temas vazios de discussões que possibilitassem aos alunos uma conscientização do seu dever cidadão, assim como propõe o próprio documento. Vejo em mim e em alguns colegas que ensinam Filosofia um esforço em aplicar a Filosofia de forma reflexiva.

\section{A CONCEPÇÃO POLÍTICA DO CURRÍCULO SÃO PAULO FAZ ESCOLA}

No discurso oficial da Secretaria da Educação São Paulo (2012) haveria duas ações na implantação. Primeiro um amplo levantamento do acervo documental e técnico pedagógico existente e segundo, um processo de consulta a escolas e professores, o segundo ato não ocorreu, ao menos não na sua maioria e sim por amostragem. Também em relação a acompanhamento e avaliação por parte dos membros da rede educacional sobre o currículo, o que ocorreu foi um sistema de avaliação e sugestões disponível no site do GDAE, entretanto, nunca utilizado, pois o material não sofreu alterações desde sua implementação.

A implementação de um currículo comum para o estado como propõe a Secretaria da educação quando diz que: "é seu dever de garantir a todos uma base comum de conhecimentos e de competências para que nossas escolas funcionem como uma rede" (SÃO PAULO, 2012 , p. 7) pode ser algo positivo, entretanto, a discussão é a imposição de tal currículo sem a participação da comunidade, pais e alunos e do corpo docente das escolas. Até porque a implementação do mesmo vai se resultar na prática docente e quando o docente não participa da sua confecção e nem ao menos é preparado para tal, os resultados geralmente não são atendidos, 
visto que "o trabalho docente é permeado por teorias e ações práticas, produz resultados no ser humano, requer reflexão teórico-prática permanente, aprofundamento e formação continuada" (FERNANDES, ano, p. 6). Para Dias e Amaral (2012, p.628) "é um currículo fechado que retira do professor o direito de conduzir sua aula, uma vez que já está pronto e padronizado".

O objetivo político para a imposição de um currículo comum ao Estado está atrelado às 10 (dez) metas da Secretaria, apresentada no capítulo anterior. Metas que visam atender as exigências do Banco Mundial, relacionado a educação. Para Rossi (2011, p.41) "há uma intenção qualitativa das ações, mas traduzida em números, caracterizando-a como um sistema verdadeiramente empresarial”. Tal fato se dá pelo baixo rendimento do Estado nas avaliações externas tanto na esfera Estadual como na esfera Federal.

Apesar de que no discurso oficial se falar em uma educação para a cultura e na importância da autonomia do aluno em que o mesmo deva "gerenciar sua própria aprendizagem para a transposição dessa aprendizagem em intervenções solidária" (SÃO PAULO, 2012, p.10) a padronização do currículo e a obrigatoriedade de ser utilizado na integra para atingir metas políticas estão ligadas a ideias neoliberais e empresariais que norteiam a política educacional no Estado de São Paulo nos últimos anos (ROSSI, 2011.) retirando da prática docente esta autonomia e sim direcionando politicamente as ideias e as intervenções que o Estado deseja.

Ao basear o novo currículo em competências e habilidades, alicerçadas pelas avaliações externas e direcionando a escola e o grupo escolar para cumprimento de metas, tem um cunho mais político do que educacional.

\section{A VOLTA DA FILOSOFIA NA GRADE CURRICULAR DO ESTADO DE SÃO PAULO E IMPLANTAÇÃO DO PROGRAMA SÃO PAULO FAZ ESCOLA.}

A disciplina de Filosofia voltou à grade curricular no Estado de São Paulo no ano de 2005 com o então Secretário da Educação Gabriel Chalita. Poucas eram as pessoas formadas em Filosofia, visto que a mesma, geralmente, era propedêutica em relação ao curso de teologia para formação Sacerdotal Católica. Não era, conquanto, uma disciplina que teria campo de trabalho, pelo fato que ela permaneceu um período fora da grade curricular. As aulas foram atribuídas, nesse momento, a ex-seminaristas e Padres ou para quem era formado em outras disciplinas que tinham na carga horária 180 horas de Filosofia. 
Inicialmente, os professores não receberam nenhuma orientação sobre o conteúdo ou currículo a ser usado na prática de aula. A orientação oferecida pelo PCNs é que o próprio professor deva optar por sua linha de docência em Filosofia no Ensino Médio, seja pela historicidade ou pela linha temática, ou seja, segundo o PCNs, caberia ao professor escolher o conteúdo. (BRASIL, 1999, p.336)

Após o início das aulas, durante o ano de 2005 , houve quatro reuniões na cidade de Serra Negra, estado de São Paulo para discutir-se a melhor maneira de aplicar-se o conteúdo da disciplina nas escolas. Um professor por diretoria de ensino era encaminhado à reunião e ficaria encarregado de propagar o discutido aos outros professores da diretoria de origem. Durante os anos de 2006 e 2007, houve nas diretorias de ensino, reuniões com os professores de Filosofia e sociologia para debaterem os conteúdos e tomarem ciência do andamento das aulas.

Já, para o ano de 2006, a Secretaria da Educação do Estado de São Paulo, solicitou ao Instituto de Filosofia e Ciências Humanas da UNICAMP (IFCH), a produção de um material para os professores. O referido serviria como diretriz das aulas a serem ministradas, cujo nome é Filosofia \& Vida: 0 ensino de Filosofia na escola pública do estado de São Paulo. O material foi produzido em quatro volumes contendo os períodos históricos da Filosofia e alguns fragmentos do pensamento de alguns filósofos. Segundo o então Secretário da Educação, Gabriel Chalita "[...] este curso pretende oferecer subsídios capazes de ampliar os conhecimentos de todos os professores que dedicam-se à propagação de saberes relacionados à Filosofia". (SÃO PAULO, 2006)

Apesar material em destaque, os professores não eram obrigados a segui-los, apenas possuíam-no como um direcionamento. No Ano de 2006, com a saída de Gabriel Chalita e a entrada de Maria Lúcia Marcondes Carvalho Vasconcelos, na secretaria da educação, houve algumas mudanças em relação à Filosofia. No mesmo ano, foi produzido pelo IFCH mais um volume da coleção que pode ser visto como um plano de atuação para os professores.

Atuando como professor da rede estadual de ensino no ano e 2008 , relato um fato ocorrido no início do ano letivo ${ }^{1}$. No portal do governo do estado de São Paulo a Secretaria da Educação esclarecia que, durante o primeiro bimestre seria oferecido

\footnotetext{
${ }^{1}$ Era então, dia 14 de fevereiro. Diante do cenário, os professores com aulas atribuídas para o ano letivo retomaram suas atividades para os três dias de planejamento antecessores ao início das aulas. Nas escolas, os professores encontraram caixas cheias de um "jornalzão" que deveriam ser usados nas aulas. Na época, nenhuma orientação por parte da Secretaria da Educação foi enviada às escolas. Diferentemente do que afirmava o documento oficial da Secretaria da Educação que: "[...] segunda feira deu início a um processo de consulta às escolas e professores para identificar, sistematizar e divulgar boas práticas existentes nas escolas de São Paulo" (SÃO PAULO, 2009). Até onde pudemos investigar, não houve efetiva e ampla consulta aos Professores, Coordenadores e Diretores da rede. Ocorrera sim, por amostragem estatística.
} 
reforço intensivo, nas disciplinas de Português e Matemática como prioridade, mas também em todas as disciplinas, para todos os alunos matriculados na rede estadual. O referido processo ocorreu devido aos baixos índices de rendimento dos alunos da rede Estadual nas avaliações externas: Prova Brasil, Saresp e Enem.

No mesmo período, a Secretaria da Educação lançou uma agenda trienal, 20082010, contendo 10 metas. São elas:

1. Todos os alunos de 8 anos plenamente alfabetizados;

2. Redução de $50 \%$ das taxas de reprovação da 8a série;

3. Redução de $50 \%$ das taxas de reprovação do Ensino Médio;

4. Implantação de programas de recuperação de aprendizagem nas séries finais de todos os ciclos de

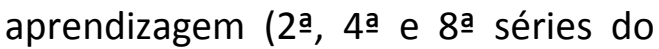
Ensino Fundamental e 3a série do Ensino Médio);

5. Aumento de $10 \%$ nos índices de desempenho do Ensino Fundamental e Médio nas avaliações nacionais e estaduais;

6. Atendimento de $100 \%$ da demanda de ${ }^{2}$ jovens e adultos de Ensino Médio com currículo profissionalizante diversificado; http://www.saopaulo.sp.gov.br/acoes/educacao/m etas/acoes.htm
7. Implantação do Ensino Fundamental de nove anos, com prioridade à municipalização das séries iniciais (1 ${ }^{a}$ a 4a séries);

8. Programas de formação continuada e capacitação da equipe;

9. Descentralização e/ou municipalização do programa de alimentação escolar nos 30 municípios ainda centralizados;

10. Programa de obras e melhorias de infraestrutura das escolas.

A partir do ano de 2009 , com o programa São Paulo Faz Escola, foi produzido e enviado a todas unidades escolares do Estado uma espécie de apostilado bimestral. Composto de um caderno de exercício a todos os estudantes e um caderno para o professor. Dividido em quatro situações de aprendizagem contendo número de aulas necessário para trabalhar competências e habilidades, conteúdo, avaliação e procedimento metodológico. Não obstante, o discurso dos Supervisores de Ensino de que o material produzido pela Secretaria é um "direcionamento" das aulas, os professores são cobrados a aplicá-lo na íntegra.

No Ano de 2009, foi reduzida a carga horária de Filosofia pela Secretaria da Educação. Sem nenhum parecer oficial; as aulas de da disciplina em questão reduziramnas a duas no primeiro ano do Ensino Médio e a uma aula no segundo ano, extinguindo-se 
no terceiro ano do Ensino Médio. Apesar de haver uma mudança na carga horária do segundo ano do Ensino Médio, não muda o material didático e a necessidade para se cumprir o programa em cada bimestre é de 19 a 22 aulas, porém a carga horária bimestral previa é de 9 a 11 aulas.

Em 2012, a Filosofia volta a ter duas aulas semanais nos três anos do Ensino Médio, tanto no período matutino quanto no vespertino. No noturno, a Filosofia fica com uma aula no primeiro ano, duas no segundo e terceiro. Não houve durante estes seis anos do apostilado uma formação para aplicação do mesmo nas escolas, apenas para os professores ingressantes no concurso de 2010. Nos anos subsequentes a sua implantação, de 2009 até 2012, bimestralmente, fez-se uma avaliação diagnóstica, pelo site DRHU sobre o conteúdo e qualidade do material. Todas as sugestões feitas pelos professores de Filosofia foram ignoradas. Tem-se conhecimento do fato, porque o autor da tese, juntamente com os professores de Filosofia da Diretoria de Santo Anastácio fizeram inúmeras sugestões sem sucesso.

Neste ano de 2014, houve uma mudança no material, não no conteúdo. Mudou-se a "capa" dos cadernos, ao invés do material ser bimestral passou a ser semestral e alguns dados foram atualizados. Do mais, tudo permanece da mesma forma. Depois de superada esta etapa de descrição da Filosofia na grade curricular e a implantação do programa São Paulo Faz Escola, vamos problematizar sobre: qual é a proposta do Estado de São Paulo com seu projeto São Paulo faz escola para a disciplina de Filosofia, com seus objetivos, conteúdos e temas, competências e habilidades.

A implantação do projeto de apostilado recebeu críticas pelo fato que os professores da rede não terem sido consultados. Ademais, os conteúdos, algumas vezes, distam da realidade da comunidade assistida. Além de não ter tido tempo de adaptação e capacitação para os professores.

\section{CONSIDERAÇÕES FINAIS}

Buscou-se analisar o pressuposto político da implantação do programa São Paulo Faz Escola, na área de Ciências Humanas e na disciplina de Filosofia. Percebe-se que apesar de um discurso oficial de que no estado de São Paulo o currículo foi uma "proposta" para melhorar as condições da aprendizagem e que houve a participação integral dos agentes de educação do estado, pudemos perceber que não foi exatamente o que aconteceu.

Volta-se a salientar que não vemos como negativos tais objetivos para a educação, mas o que questionamos são os tipos de cidadania e trabalho que se deseja 
com este currículo. A cidadania desejada é que os alunos simplesmente cumpram suas obrigações sem discussão ou manifestação contrárias aquilo que o estado impõe. Em relação aos postos de trabalho os estudantes da escola pública estão sendo direcionados a profissões sem muita especialização, ou seja um tipo de operários.

Sobre a Filosofia o currículo a projeta como uma disciplina que não causa o "espanto" e a reflexão desejada para a mesma. Percebe-se que a disciplina esta posta como um souvenir. Os temas e os textos escolhidos não contribuem para uma reflexão do mundo do trabalho e da cidadania atual. Assim a mesma seria uma disciplina que "com a qual ou sem a qual o mundo continua tal e qual".

\section{REFERÊNCIAS}

BRASIL. Secretaria de Educação Fundamental. Parâmetros curriculares nacionais: terceiro e quarto ciclos do ensino fundamental: introdução aos parâmetros curriculares nacionais. Brasília: MEC/SEF, 1999.

DIAS, S. F.; AMARAL, C.L.C. Anais do II Seminário Hispano Brasileiro - CTS, p. 627634, 2012.

FERNANDES, S. F. . As Políticas Públicas e o Trabalho Docente na Implementação da Proposta Pedagógica no Estado de São Paulo: entre o compromisso individual e a responsabilidade institucional. 2010.

ROSSI, M. A nova proposta curricular do ensino de geografia na rede estadual de São Paulo: um estudo. 2011. Dissertação (Mestrado em Educação) - Faculdade de
Filosofia, Letras e Ciências Humanas USP, São Paulo - SP.

SÃO PAULO (Estado). Filosofia: o ensino de Filosofia na escola pública do Estado de São Paulo. V volumes. São Paulo, 2006.

SÃO PAULO (Estado). Currículo do Estado de São Paulo: ciências humanas e suas tecnologias Ensino Médio Secretaria de Educação. São Paulo: SEE, 2009.

SÃO PAULO (Estado). Ciências humanas e suas tecnologias. Caderno do professor, Primeiro, Segundo e Terceiro anos, vol. 1 e 2. Ensino Médio Secretaria de Educação. São Paulo: SEE, 2014a.

SÃO PAULO (Estado). Ciências humanas e suas tecnologias. Caderno do aluno primeiro, Segundo e Terceiro anos, vol. 1 e 2. Ensino Médio Secretaria de Educação. São Paulo: SEE, 2014b.

Recebido para publicação em 19/08/2014 Revisado em 25/08/2014 Aceito em 28/08/2014 